Rüdiger Voigt bildet gleichzeitig den mit „Parlamentarismus und freies Mandat“ überschriebenen letzten Themenblock, wobei der Autor zentrale Schwerpunkte von Burkes Denken pointiert. $\mathrm{Zu}$ nennen sind etwa sein Verständnis des Staates als „geronnene historische Vernunft“ (S. 245) oder seine „merkwürdige, wenn nicht reaktionäre Demokratievorstellung“ (S. 246). Leider wurde der multiperspektivische Zuschnitt der vorangehenden drei Kapitel hier nicht weitergeführt, was den rundum gelungenen Sammelband etwas abrupt zu einem Ende kommen lässt.

Funding Open Access funding enabled and organized by Projekt DEAL.

Open Access Dieser Artikel wird unter der Creative Commons Namensnennung 4.0 International Lizenz veröffentlicht, welche die Nutzung, Vervielfältigung, Bearbeitung, Verbreitung und Wiedergabe in jeglichem Medium und Format erlaubt, sofern Sie den/die ursprünglichen Autor(en) und die Quelle ordnungsgemäß nennen, einen Link zur Creative Commons Lizenz beifügen und angeben, ob Änderungen vorgenommen wurden.

Die in diesem Artikel enthaltenen Bilder und sonstiges Drittmaterial unterliegen ebenfalls der genannten Creative Commons Lizenz, sofern sich aus der Abbildungslegende nichts anderes ergibt. Sofern das betreffende Material nicht unter der genannten Creative Commons Lizenz steht und die betreffende Handlung nicht nach gesetzlichen Vorschriften erlaubt ist, ist für die oben aufgeführten Weiterverwendungen des Materials die Einwilligung des jeweiligen Rechteinhabers einzuholen.

Weitere Details zur Lizenz entnehmen Sie bitte der Lizenzinformation auf http://creativecommons.org/ licenses/by/4.0/deed.de.

\title{
Kroll, Thomas/Severin-Barboutie, Bettina (Hrsg.): Wider den Kapitalismus. Antikapitalismen in der Moderne, 294 S., Campus, Frankfurt a.M. u.a. 2021.
}

\section{Anette Schlimm}

Angenommen: 17. Dezember 2021 / Online publiziert: 24. Januar 2022

(C) Der/die Autor(en) 2022

Er war eine Irritation für die bundesdeutsche Gesellschaft und löste einen veritablen Skandal aus: Hannsheinz Porst war Millionär und Mitglied in der FDP - gleichzeitig aber auch in der SED. 1969 wurde er für seine Zusammenarbeit mit dem Ministerium für Staatssicherheit zu 33 Monaten Gefängnis verurteilt. War er nun ein Kapitalist

Anette Schlimm $(\bowtie)$

Ludwig-Maximilians-Universität, München, Deutschland

E-Mail: anette.schlimm@1rz.uni-muenchen.de 
oder ein Kommunist? An Porsts Beispiel zeigt Eva-Maria Gajek, wie sehr sich Kapitalismus und Antikapitalismus ineinander verschlingen konnten.

Solche Fallstudien sind es, die im vorliegenden Band das Verhältnis von Kapitalismus und Antikapitalismus und ihren jeweils sehr unterschiedlichen Erscheinungsformen verdeutlichen. Sie verdeutlichen auch, dass ihr Verhältnis eben nicht auf einen einfachen Nenner gebracht werden kann. Antikapitalismus ist mehr als nur die Kehrseite des Kapitalismus, er ist ein historisches Phänomen „sui generis“ (S. 12), das noch dazu äußerst vielfältig und schillernd ist, so dass es am besten im Plural, als „Antikapitalismen“ (S. 14) bezeichnet werden sollte, wie die Herausgeber_innen in der Einleitung ausführen.

Zur Organisation der Geschichte des Antikapitalismus schlagen sie außerdem ein zeitliches Phasenmodell vor. Sie beobachten fünf besondere Verdichtungsphasen der Kapitalismuskritik seit 1800: im frühen 19. Jahrhundert, in der Phase der Hochindustrialisierung um 1870, in den 1920er/30er Jahren, den 1970er/80er Jahren und nun wieder seit den frühen 2000er Jahren. Wirtschaftskrisen spielten also, so die Annahme, für die Kapitalismuskritik eine wichtige Rolle, schufen sie doch ein gesellschaftliches Klima, in dem Antikapitalismen florierten. Doch verliefen die Geschichten von Kapitalismus und Antikapitalismen tatsächlich so synchron? Jonathan Sperber zeigt in seiner Analyse der Marx'schen Kritik am Kapitalismus, dass sie nicht der Beobachtung von Marx' eigener Gegenwart entsprang. Vielmehr war Marx ,vor allem ein Kritiker des Kapitalismus des frühen 19. Jahrhunderts“ (S. 50); daher rührte auch sein Fokus auf Verelendung und Entfremdung der entstehenden Arbeiterklasse. Insofern ist die Ideengeschichte des Marxismus ein sehr wichtiger Hinweis auf die Eigenzeitlichkeit der Antikapitalismen. Je ernster man sie als eigenständiges Phänomen nimmt, umso schwerer fällt es, sie in eine Chronologie des Kapitalismus hineinzupressen.

In der Kapitalismuskritik spielten vor allem im 20. Jahrhundert die globalen ,Anderen“ eine wichtige Rolle. Hier muss geklärt werden: Wurden die Bewohner_innen des globalen Südens in den Antikapitalismen des globalen Nordens außerhalb des Kapitalismus angesiedelt? Oder wurden sie als Teil einer einzigen globalen kapitalistischen Weltordnung verstanden? Timo Luks skizziert in seinem Beitrag die Rolle, welche die „Ökonomie der Anderen“ für die unterschiedlichen Formen der Kapitalismuskritik in der französischen Anthropologie des 20. Jahrhunderts spielte. Während Marcel Mauss im Gabentausch das Modell für eine antikapitalistische Ökonomie erblickte und damit die ,Anderen“ in einer Welt außerhalb des Kapitalismus verortete, versuchte Claude Lévi-Strauss, die ökonomischen Praktiken im globalen Süden eben gerade als Ergebnis kapitalistischer Ausbeutungs- und Gewaltverhältnisse zu lesen. Dietmar Süß widmet sich in seinem Aufsatz den solidarischen Praktiken westdeutscher Aktivist_innen, die vor allem nach Lateinamerika zielten. Die Begegnung mit den Lateinamerikaner_innen sollte, so der Plan, die Aktivist_innen mit Erfahrungen ausstatten, die ihnen bei der eigenen Arbeit gegen das kapitalistische System in Westdeutschland zugutekommen sollten. Gleichwohl ließ sich die Begegnung mit den ,Anderen “ nur schwer planen, produzierte sie Irritationen und Sprachlosigkeiten.

Die Herausgeber_innen betonen in der Einleitung, dass die Antikapitalismen die Moderne dadurch stark beeinflusst hätten, dass der Kapitalismus Kritiken und Gegenentwürfe aufnahm und integrierte. Bettina Severin-Barboutie widmet sich dem 
Versuch von lebensreformerischen Akteuren um 1900, im Pazifik einen „Sonnenorden“ zu gründen, ein besonders naturgemäßes Leben zu führen und den Kapitalismus zu überwinden. Jedoch war der ,Sonnenorden“ nicht jenseits des Kapitalismus angesiedelt, sondern ein besonderer Teil von ihm. Die körperlich anstrengende Arbeit auf der Kokosplantage wurde von indigenen Arbeiter_innen verrichtet, die möglicherweise gewaltsam auf die Pazifikinsel Kabakon verschleppt worden waren und nun in kolonialen Abhängigkeitsverhältnissen lebten. Außerdem exportierte der ,Sonnenorden“ - gewinnbringend - Kopra, also Kokosnussfleisch, um zur Überwindung des Fleischkonsums beizutragen. Frank Becker wiederum untersucht das nationalsozialistische „Amt für Betriebsführung und Berufserziehung“(AfBuB), in dem ein spezifisch antikapitalistischer Arbeitsbegriff entwickelt wurde. Statt entfremdeter Arbeit in ,bolschewistischen “ oder kapitalistischen Gesellschaften sollten die Menschen im nationalsozialistischen Deutschland einer Arbeit nachgehen, die durch Leistung, Gemeinschaft und Gestaltung gekennzeichnet sei. Was in den 1930er Jahren noch als Gegenbild zum Kapitalismus entworfen wurde, begegnet uns heute möglicherweise in ähnlicher Form in den Arbeitsethiken von hochkapitalistischen Unternehmen der Digital- und Kreativwirtschaft. Sicherlich gibt es keine einfache Kontinuität von der nationalsozialistischen Arbeitsethik bis ,new work“, doch es ist die Aufgabe, der Historiker_in, hier genauer hinzuschauen und komplexe Zusammenhänge sichtbar zu machen.

Der Band ist eine anregende Lektüre für all diejenigen, die sich für Praktiken und Ideen am Rande des Kapitalismus interessieren, die danach fragen wollen, wie sich kapitalistische Wirtschaftsweisen und Kulturen verändert haben und wie vielfältig sie waren. Dass er das Verhältnis von Kapitalismen und Antikapitalismen letztlich analytisch nicht ausbuchstabiert, ist schade, aber auch dem Medium des Tagungsbandes geschuldet. So bleibt es anderen Publikationen überlassen, dieses Verhältnis weiter zu ergründen.

Funding Open Access funding enabled and organized by Projekt DEAL.

Open Access Dieser Artikel wird unter der Creative Commons Namensnennung 4.0 International Lizenz veröffentlicht, welche die Nutzung, Vervielfältigung, Bearbeitung, Verbreitung und Wiedergabe in jeglichem Medium und Format erlaubt, sofern Sie den/die ursprünglichen Autor(en) und die Quelle ordnungsgemäß nennen, einen Link zur Creative Commons Lizenz beifügen und angeben, ob Änderungen vorgenommen wurden.

Die in diesem Artikel enthaltenen Bilder und sonstiges Drittmaterial unterliegen ebenfalls der genannten Creative Commons Lizenz, sofern sich aus der Abbildungslegende nichts anderes ergibt. Sofern das betreffende Material nicht unter der genannten Creative Commons Lizenz steht und die betreffende Handlung nicht nach gesetzlichen Vorschriften erlaubt ist, ist für die oben aufgeführten Weiterverwendungen des Materials die Einwilligung des jeweiligen Rechteinhabers einzuholen.

Weitere Details zur Lizenz entnehmen Sie bitte der Lizenzinformation auf http://creativecommons.org/ licenses/by/4.0/deed.de. 